\title{
Testing healthcare staff for infection with HIV and hepatitis: logistic and ethical considerations
}

\author{
A Newell, S E Barton
}

\section{Introduction}

The issue of whether to test healthcare workers for the presence of blood borne viruses arouses much controversy and indignation. Unfortunately, the heat of this debate has often been fuelled by media sensationalistm or medical examples of shroud waving, which have served to obfuscate the real issues which lie at the heart of this proposal. This review will focus on three virus infections, HIV, hepatitis B virus (HBV) and hepatitis $C$ virus (HCV).

To examine the ethical considerations involved in this question properly, it is necessary to understand the natural history, potential for vaccination and available treatment of each of these conditions, as well as review the evidence that an infected healthcare worker poses any risk to the health of their patients. Only on this basis can one judge whether or not mandatory testing of healthcare workers will benefit the individual healthcare worker and/or their employees and/or their patients and/or society at large. By examining the pros and cons of such proposed testing regimes for each of these groups, a balanced decision on the ethical issues can be reached. Once the ethical balances have been set, it will be possible to assess the logistics and costs in obtaining this supposed benefit which would accrue from the testing of healthcare workers. In the real life debate, this decision and who makes it seems most likely to determine the future course of policy and practice.

Genitourinary

Medicine,

St Stephen's Clinic, Chelsea and

Westminster Hospital,

369 Fulham Road,

London SW10 9TH

A Newell

S E Barton

Correspondence to: Dr S E Barton.

Accepted for publication Accepted for pub
13 March 1995

\section{The viruses concerned}

The salient features of the three viruses, HIV, $\mathrm{HBV}$ and HCV, are summarised in the table. Several important differences need to be emphasised. From HIV acquisition, an infected individual remains infectious to a greater or lesser degree throughout the rest of his/her life.
There are no reported or substantiated cases of naturally acquired or treatment induced eradication of HIV infection.

In contrast, only a small percentage of individuals infected by HBV will be infectious to others for more than a few months after infection. There are well validated laboratory tests to identify these individuals and treatments offer the possibility of reducing or even removing infectivity. Furthermore, in the case of $\mathrm{HBV}$ infection there is an effective and safe vaccine which will prevent infection in the majority of recipients.

Neither HIV nor HCV have an adequate vaccine available at present. ${ }^{1}$ Tests are only just beginning to be available for HCV infectivity, which, on present data, is presumed to be for life in up to $50 \%$ of infected individuals. Although treatment exists to reduce the severity of HCV induced hepatitis, there is little evidence of an effect on the transmission of this infection.

\section{Evidence of transmission of infections} between patients and healthcare workers There have been documented cases of transmission of both HIV and HBV from healthcare workers to patients, ${ }^{2-6}$ and reports of all three viruses being transmitted from patients to healthcare workers. ${ }^{7-11}$ Over the past four years, the major concern amongst the general population about the risk of becoming infected by healthcare workers has centred on those with HIV infection. This has been amplified by specific reports, especially the transmission of HIV from a Florida dentist with the acquired immunodeficiency syndrome to five of his patients, ${ }^{3}$ and the UK media response to the reports of HIV infected healthcare workers in 1991 and 1993. These incidents have precipitated the call for mandatory HIV antibody

Clinical features of $H I V, H B V$ and $H C V$

\begin{tabular}{|c|c|c|c|}
\hline Features & $H I V$ & $H B V$ & $H C V$ \\
\hline $\begin{array}{l}\text { Clinical outcome } \\
\text { acute } \\
\text { chronic }\end{array}$ & $\begin{array}{l}\text { Very rarely fatal; }<1 \% \text { present with symptoms } \\
\text { Immunosuppression leading to AIDS; } \\
\text { opportunistic infections; neoplasia }\end{array}$ & $\begin{array}{l}<5 \% \text { develop acute fulminant hepatitis } \\
\text { Chronic persistent hepatitis; chronic } \\
\text { active hepatitis; cirrhosis; primary } \\
\text { hepatocellular carcinoma }\end{array}$ & $\begin{array}{l}\text { Acute hepatitis } \\
\text { Chronic persistent hepatitis; chronic } \\
\text { active hepatitis; cirrhosis; primary } \\
\text { hepatocellular carcinoma }\end{array}$ \\
\hline $\begin{array}{l}\text { Vaccination } \\
\text { Treatment } \\
\text { Carriage/infectivity }\end{array}$ & $\begin{array}{l}\text { None available-research stage only } \\
\text { Antiretroviral therapy, e.g. AZT, ddI, ddC } \\
\text { Persistent }\end{array}$ & $\begin{array}{l}\text { Available }>95 \% \text { successful } \\
\text { Interferon- } \alpha \\
\text { HBeAg persists in } 7-10 \%\end{array}$ & $\begin{array}{l}\text { None available-research stage only } \\
\text { Interferon- } \alpha \\
30-50 \% \text { carriage rates: infectivity } \\
\text { uncertain }\end{array}$ \\
\hline
\end{tabular}


testing of healthcare workers. Overseas, it has recently been reported that in New South Wales, Australia, six monthly testing of doctors, dentists and nurses is being planned. ${ }^{12}$ But what is the real risk of patients becoming infected by a HIV seropositive healthcare worker?

At present, there are no data concerning the HIV seropositivity rate amongst healthcare workers in the UK. Researchers have, using available information, attempted to estimate the risk to patients of acquiring HIV per hour of surgery and have put the risk in the region of one chance in 21 million per hour of surgery. ${ }^{13}$

As stated by Lowenfels and Wormser, ${ }^{13}$ the risks are clearly low and might be of the same magnitude as a fatal injury to the patient en route to the hospital. In considering transmission, retrospective investigations conducted mainly in the USA, ${ }^{14-17}$ but also in the UK, ${ }^{18}$ have emphasised that the risk to patients is low. However, it has been noted that in these retrospective studies testing is voluntary ${ }^{17}$ and that within the self-selected group who choose not to be tested the possibility remains that a HIV infected person may be undetected and therefore the real risk has not been calculated.

\section{Current guidelines in the UK}

At present, the Department of Health guidelines ${ }^{19}$ state that "all healthcare workers are under an overriding ethical as well as legal duty, to protect the health and safety of the patients and that those who believe they may have been exposed to infection with HIV must seek medical advice and diagnostic HIV antibody testing, if appropriate". Furthermore, "all healthcare workers who are infected with HIV seek appropriate medical care and also occupational health advice and must cease from performing exposure prone procedures. Physicians or occupational health practitioners who are aware that an infected healthcare worker is continuing to perform exposure prone procedures should inform the regulatory body and also the Director of Public Health, in confidence". However, fears about loss of financial security, career and confidentiality have resulted in these guidelines being ignored by some healthcare workers. This has added support to the call for mandatory testing to be instituted.

In August 1993 the NHS management executive $^{20}$ recommended that all healthcare workers should be immunised against hepatitis $\mathrm{B}$, not only to protect patients against acquiring hepatitis B from an infected healthcare worker but also to ensure that healthcare workers are protected from their patients where the risk of infection from a single exposure to e antigen blood is as high as $30 \%$. It also stated that doctors found to be infectious-that is, e antigen positive, cannot do any invasive or exposure prone work. All surgeons and other healthcare workers involved in invasive work are now being tested.

As yet, there is no legislation concerning healthcare workers infected with HCV. There have been no reports of a healthcare worker with hepatitis $C$ infecting a patient, although there have been many reports of healthcare workers being infected by patients. This can be explained by a number of factors. The number of healthcare workers with hepatitis $C$ is low and probably matches that of the local blood donor population, estimated to be 1 in $2000,{ }^{21}$ and, as yet, no retrospective studies involving $\mathrm{HCV}$ infected healthcare workers have been performed. At present, therefore, the institution of screening of healthcare workers for HCV appears unfounded.

\section{Ethical issues of mandatory testing}

Next we will examine the issues for individual doctors, their patients, their employers, their educators, and for society in general.

\section{THE HEALTHCARE WORKER}

A healthcare worker who tested HIV antibody positive would be bound by professional responsibility to review and amend their working practices to remove the risk of infecting their patients. Clearly the extent to which a general practitioner or a surgeon has to change their practice will vary considerably.

The same principle would be clearly true for healthcare workers who have surface antigen positive hepatitis B or who have tested positive for HCV. However, although an individual healthcare worker may be driven towards the "first do no harm principle", their personal change in circumstances and work practices may influence their decision or its timing. Although we ought to be able to feel secure that a potentially infectious doctor or nurse would be driven by expected altruism to modify their practices, cases may occur where the individual may feel reluctant to amend their practice or stop working for financial reasons. This has recently been highlighted by the case of the surgeon who had hepatitis B and who continued working in order to support himself and his family. ${ }^{22}$

In the case of transmission of hepatitis B from healthcare workers to patients, it is clear that this should be avoidable by the delivery of the safe and effective vaccine which, although it has been in clinical use for over 10 years, has received a poor response by healthcare workers. Reasons for not being vaccinated often demonstrate ignorance of the safety ${ }^{2324}$ of the vaccine or reflect the lack of any coordinated policy. The new policy to provide vaccination to all staff involved in invasive procedures is most welcome. However, in the interim period until the completion of this vaccination schedule there remains the question whether or not routine testing for hepatitis $B$ antigens should be recommended, especially amongst surgeons and theatre staff.

In the light of a recent infection of a patient in Sunderland from a surgeon who was discovered to have hepatitis $B$, the Chairman of the NHS Trust Federation's Human Resources Committee is quoted as recommending that doctors should have an immunisation certificate. ${ }^{25}$ Such a suggestion raises several important issues. To be immunised against hepatitis $B$ is clearly in the best interest of 
healthcare workers as it will protect them from contracting hepatitis B from infected patients. On the other hand, those individuals who have not yet been vaccinated either because of their own or their health authority's intransigence may have already contracted hepatitis B, and in those cases where e antigenaemia is present would have to modify their practice. Closing the loop to satisfy the needs of both healthcare workers and their patients requires clear guidance on the financial and social treatment which doctors and other healthcare workers will face if they are found to be e antigen positive. This should include the option for treatment with interferon which may increase seroconversion and permit them to return to work. Failing this, the clear onus should be on the NHS to ensure that a coordinated response encourages healthcare workers to act in the best interest of their patients and themselves. At present, the NHS Injury Benefit Scheme allows for up to $85 \%$ of pre-injury NHS earnings. However, it states that "it must be established that the injury or disease was acquired during the course of work", something which the legal department of one journal describes as "next to impossible". ${ }^{26}$ If financial reimbursement was made available to all NHS employees found to be infectious, the reticence for self-identification would at least be partially alleviated. The origin of the infection should not influence the right to, or size of, reimbursement.

At present, there appears to be no central government guidelines. New BMA guidelines are due in the near future to try and unravel this conundrum.

\section{THE PATIENT}

Many policy decisions are currently implemented as a result of patient choice. However, at present, we have no data to indicate that patients wish healthcare workers to be screened for HIV. If mandatory testing of healthcare workers for HIV was implemented, patients might consider themselves to be at no risk of infection from their attending healthcare worker. This would create a false sense of security, as it is well documented that a recently infected individual can be HIV antibody negative but viraemic and infectious. However, the situation has been further complicated recently by the report of patient to patient transmission of HIV in a private surgical consulting room where the operating surgeon was HIV antibody negative. ${ }^{27}$ This poses a further dilemma, namely the question of whether all patients should be screened before surgery to protect other patients from infection, let alone the surgeon and other theatre staff.

Once, as proposed, all healthcare workers involved in invasive procedures are known to have seroconverted to vaccination against hepatitis $B$, the risk to patients of contracting this condition will effectively be removed and will clearly provide reassurance for patients.

THE EMPLOYER

Should mandatory HIV antibody testing be instituted, it is possible that NHS hospitals and trusts would be tempted to promote themselves as being a safer environment for patients.

The present cost of performing a HIV antibody test is approximately $£ 6.00$ (excluding costs for counselling). In the UK there are over 11850 doctors who perform invasive procedures (gynaecologists, obstetricians, surgeons, and dentists). ${ }^{28}$ Thus, if screening was to be instituted four times per year, the predicted cost would be in excess of $£ 285000$ per annum to prevent what so far has been an undocumented occurrence in this country. It is interesting to note that prior to the release of the Department of Health guidelines, the BMA response advised that routine screening of healthcare workers undertaking invasive procedures as a measure to protect patients from infection is not justified. ${ }^{29}$ Unfortunately, this opinion was not included in the final document.

Mandatory hepatitis B screening and vaccination will prevent accidental infection of both patients and healthcare workers. It should also prevent doctors who conceal their carrier status from jeopardising the health of their patients. Screening/identification of infectious healthcare workers should be administered centrally. A database of all infectious healthcare workers could be collated. When a Hospital Authority/Trust appoint a healthcare worker to a position (associated with invasive procedures) the files could be confidentially consulted. This, in turn, will prevent litigation against hospitals and trusts. This is particularly pertinent as the Medical Defence Union regards a known e antigen positive surgeon performing invasive procedures as indefensible. ${ }^{30}$

\section{THE PUBLIC}

We must consider the effect that such a policy would have on public perception of the risk of HIV transmission. Only recently, a high profile London store became embroiled in a row over alleged compulsory testing of its food hall staff for HIV antibodies. ${ }^{31}$ This fuels unnecessary fear and prejudice and would be further exacerbated should the Department of Health require the same of its healthcare workers. Furthermore, such a policy may alter public perception such that healthcare workers would be regarded as a potential source of HIV infection.

A possible scenario in any public debate is the search for a compromise. In this context, it is hoped that the obvious concentration on risks to patients from surgeons and others who regularly perform the most exposure prone procedures will not lead to a split in the health requirements of different doctors and healthcare workers.

\section{THE EDUCATOR}

More recently, there has been much discussion over the introduction of vetting medical and dental students before entry to medical school. ${ }^{32-34}$ The Committee of Vice Chancellors and Principals has issued guidelines which are to come into force by 1996 which state that 
successful applicants must have proof "of non infectivity and immunisation against hepatitis B by the time of registration". ${ }^{35}$ This has resulted already in one applicant being refused entry on these grounds. ${ }^{36}$

It is being argued that this policy is an overreaction and will deny prospective medical students careers in lower risk specialties such as psychiatry, microbiology, etc., and will inadvertently discriminate against applicants from countries where carrier rates are higher. It also precludes the possibility of successful treatment with interferon. However, screening of prospective medical students at secondary school will identify those individuals deemed to be infectious early on when they have the greatest chance of adapting to a new career, as opposed to being identified either half way through their medical training or once they have infected their patients. A compromise might be that secondary school screening and immunisation would allow those identified as infectious to either switch career or continue into medical school and go into modified courses leading to non-invasive careers. If therapy or natural history altered their infectious status then, this could act as a module for transferring to the full medical course.

\section{Ethical balance}

In summary, for hepatitis B infection it is clear that it is in the best of interests of both healthcare workers and patients that all healthcare workers are vaccinated and protected from acquiring HBV infection and hence this will prevent patients being at risk of infection. The only negative aspects to this are potentially in those individuals in whom vaccination does not promote a sufficient immune response or those individuals who are already infected with hepatitis $B$ and remain antigenaemic. The provision of clear indications for the financial and professional management of these individuals is long overdue. By minimising the negative aspect of the knowledge of antigen positivity for the individual healthcare worker, central government can add great emphasis to the screening system and help to maintain the safety of patients.

In the case of HIV infection no such vaccine exists, but the potential risk to patients is less well defined. For the individual healthcare worker the knowledge of their own HIV seropositivity would be a cause of personal health concern, but surely knowledge that they had exposed patients to an infectious risk may be an even greater psychological burden to bear. Ethically, responsibility lies with the individual to weigh up their own personal risk of HIV seropositivity before deciding whether to have a HIV test. There is no evidence that compulsory testing in any context has been beneficial either to individuals or to potential contacts. Clearly, a reappraisal of the needs to test healthcare workers compulsorily would need to be accompanied by a consideration of whether or not to test all patients undergoing invasive procedures similarly.

In the case of hepatitis C little is known about the risk of occupational transmission of this infection, hence in the absence of clear knowledge the ethical principles outlined above should apply. Mandatory testing of either healthcare workers or the general public does not appear to be of value at present.

\section{Logistics}

If the government was to institute a policy for HIV or HCV testing of healthcare workers there are a number of logistical considerations to be considered.

How frequently would healthcare workers be screened in view of the well documented three month window between infection and seroconversion? Should screening of all healthcare workers be instituted or should it only be targeted at those individuals who perform invasive procedures?

Another dilemma is posed by the situation of visiting specialists and locums from abroad who may be infected. Would they be tested on arrival and expected to wait three months before being allowed to work in this country?

Yet another concern has been raised about the stance the Association of British Insurers would take on compulsory testing of healthcare workers. They have stated that if an applicant has a routine negative test, an extra premium will not be charged unless risk factors are present, be they disease, lifestyle or occupation. ${ }^{37}$

\section{Conclusion}

The screening of healthcare workers for blood borne viruses has been hotly debated and, at present, the risk to patients appears to stem mainly from those surgeons identified as carrying hepatitis e antigen and therefore mandatory blanket screening of healthcare workers for HCV and HIV appears unfounded. However, it is the clear moral obligation of all healthcare workers to protect the health of their patients. If the profession fails, either singly or collectively, to honour this contract it can be envisaged that central government or individual Trusts will set the future agenda and thus impose their own level of testing. By emphasising professional obligations and supporting the hepatitis $B$ prevention scheme, all doctors will demonstrate clearly their willingness and ability to act in the very best interests of their patients. The results of "lookbacks" on the patients of healthcare workers known to have HIV infection, and studies of the transmission characteristics of HCV should inform future decisions regarding testing for these viruses. It is hoped that this will constitute a prime example of repeated negative studies supporting common sense and good ethical and medical practice.

Thanks are due to $\operatorname{Dr} \mathbf{R}$ Gillon for his helpful advice and comments and to Hilary Gough for typing the manuscript.

1 Vaccine against AIDS. Lancet 1994;343:493-4.

Ou CY, Ciesielski CA, Maars G, Bandea CI, Luo CC Korber BT, et al. Molecular epidemiology of HIV transmission in a dental practice. Science 1992;256:1165-71.

3 Ciesielski C, Marianos D, Ou CY, Dumbaugh R, Witte J, Berkelman $\mathrm{R}$, et al. Transmission of human immunodeficiency virus in a dental practice. Ann Intern Med 1992;116:798-805. 
4 Heptonstall J. Outbreaks of hepatitis B virus infection associated with infected surgical staff. Communicable Disease Report 1991;1:R81-5.

5 Welch J, Webster M, Tilzey AJ, Noah ND, Banatvala JE. Hepatitis B infections after gynaecological surgeryCommunicable Disease. Lancet 1989;ii:205-7.

6 Shaw FE, Barrett CL, Hamm R, Coleman PJ, Hadler SC Fields HA, et al. Lethal outbreak of hepatitis B in a dental Fields HA, et al. Lethal outbreak of
practice. $f A M A 1986 ; 255: 3260-4$.

7 Marcus $\mathrm{R}$ and the CDC Co-operative needlestick surMarcus $R$ and the $C D C$ co-operative needlestick sur-
veillance group. Surveillance of health care workers exposed to blood from patients infected with the human immunodeficiency virus. $N$ Engl $f$ Med 1988;1118-23.

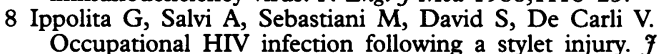
AIDS 1994;7:208-9.

9 Shanson DC. Hepatitis B outbreak in operating theatre and intensive care unit staff. Lancet 1980;ii:596.

10 Sodeyama T, Kiyosawa K, Urushihara A, Matsumoto A Tanaka E, Furuta $S$, et al. Detection of hepatitis $C$ virus markers and hepatitis $C$ virus genomic-RNA after needlestick accidents. Arch Intern Med 1993;153:1565-72.

11 Taude K, Fujiyama S, Sato S, Kawano S, Taura Y, Yoshida $\mathrm{K}$, et al. Two cases of accidental transmission of hepatitis $\mathrm{C}$ to medical staff. Hepatogastroenterology 1992;39:73-5.

12 Zinn C. New infection controls worry doctors in Australia. BMF 1994;309:497.

13 Lowenfels AB, Wormser G. Risk of transmission of HIV from surgeon to patient. $N$ Engl $\mathcal{F}$ Med 1991;325:888-9.

14 Dickinson M, Morhart RE, Klimas NG, Bandea CI, Laracuente JM, Bisno AL. Absence of HIV transmission from an infected dentist to his patients. An epidemiological and DNA sequence analysis. $\mathfrak{F} A M A$ 1993;269:1802-6.

15 Mishu B, Schaffner W, Horan JM, Wood LH, Hutcheson $\mathrm{RH}, \mathrm{McNabb}$ PC. A surgeon with AIDS: lack of evidence of transmission to patients. $¥ A M A$ 1990;264:467-70.

16 Danila RN, MacDonald KL, Rhames FS, Moen ME, Reier DO, Le Toureau JC. A look-back investigation of patients of an HIV infected physician: public health implications. $N$ Engl f Med 1991;325:1406-11.

17 Von Reyn CF, Gilvert TT, Shaw FE, Parsonnet KC, Abramson JE, Smith MG, et al. Absence of HIV transmission from an infected orthopaedic surgeon: a 13-year lookback study. $\mathscr{F} A M A$ 1993;269:1807-11.

18 Porter JD, Cruickshank JG, Gentle PH, Robinson RG, Gil ON. Management of patients treated by surgeon with HIV infection. Lancet 1990;335:113-14.

19 NHS Management Executive. AIDS-HIV infected health care workers: guidance on the management of infected health care workers. Lancashire: Department of Health, 1994. (Health service guidelines HSG(94)16.)

20 NHS Management Executive. Protecting health care worker and patients from hepatitis $B$. Lancashire: Department of Health, 1993. (Health service guidelines HSG(93)40.

21 Irving WL, Neal KR, Underwood JC, Simmonds PN, James V. Chronic hepatitis in United Kingdom blood donors infected with hepatitis C virus. BMF 1994;308:695.

22 Hunt L. Surgeon who lied about hepatitis B jailed. The Independent 1994 Sept 30; col 4

23 Smith N, Nandwani R, Daniels D. An audit of uptake of hepatitis B immunisation amongst hospital doctors. Int $\mathcal{f}$ STD AIDS 1993:4:180-3.

24 Thomas DL, Factor SH, Kelen GD, Washington AS, Taylor E, Quinn TC. The seroprevalence of and risk factors for hepatitis B virus and hepatitis C virus infection. Arch Intern Med 1993;153:1705-12.

25 Dawe V. Compulsory jabs to stem hepatitis B alarm. Hospital Doctor 21.10.94:1

26 Whyman A. Hepatitis B: careers cut short. Doctor's Post 1994. 3-5

27 Chant K, Lowe D, Rubin G, Manning N, O'Donoughue $\mathrm{R}$, Lyle $\mathrm{D}$, et al. Patient-to-patient transmission of HIV in private surgical consulting rooms. Lancet 1993;342. in private

28 Department of Health. Health and personal services statistics for England. London: HMSO, 1993.

29 British Medical Association Foundation for AIDS. AIDS HIV infected health care workers EL(93)24. Guidance on the management of infected health care workers. Practical guidance on notifying patients.

30 Tomkins C. HIV transmission from doctors to patients Fournal of the Medical Defence Union 1991;3:50.

31 Harrods spark HIV testing row. The Pink Paper 1994. Issue 330:1

32 Poland GA. Vetting medical school applicants on basis of potential hepatitis B transmission. Lancet 1994;343:1162.

33 Lever AM. Hepatitis B and medical student admission. BMF 1994;308:870-1.

34 Entry to medical school: by examination and vaccination? Lancet 1994;343:927-8.

35 Committee of Vice-Chancellors and Principals of the Universities of the United Kingdom. CVCP guidance on fitness to practice: hepatitis $B$. London: Committee of Vice-Chan cellors and Principals of the Universities of the United Kingdom, 1994

36 Thompson C. HBeAg vetting of UK medical student applicants. Lancet 1994;343:785.

37 Reynolds MA. Insurers don't penalise if test result negative [letter]. BMF 1993;307:204. 